\title{
COMPRENSIÓN DEL PRINCIPIO "COMPETENCIA-COMPETENCIA" Y CONFIGURACIÓN DE LA NULIDAD O INEFICACIA DEL ACUERDO ARBITRAL
}

\section{María Fernanda Vásquez Palma}

Doctora por la Universidad Complutense de Madrid

Profesora de Derecho Comercial, Universidad de Talca

Se me ha solicitado emitir una opinión legal sobre la posible nulidad que podrá afectar a la cláusula de arbitraje que luego se indica, y la determinación del tribunal competente para conocer de esta materia. Para una mejor ordenación, relataré primero los hechos y la discusión jurídica, luego me abocaré al principio "Competencia-Competencia", que motiva la excepción dilatoria de incompetencia que se ha formulado; y finalizaré, con la materia de fondo debatida en esta causa, esto es, la posible nulidad o ineficacia del acuerdo arbitral.

\section{SíNTESIS DE LA DISCUSIÓN JURÍDICA}

CMPC Celulosa S.A. interpuso demanda de nulidad del acuerdo arbitral inserto en la cláusula $18^{\circ}$ del contrato de seguro que suscribió con Chilena Consolidada Seguros Generales S.A., y RSA Seguros Chile S.A., continuadora legal de Compañía de Seguros Cruz del Sur S.A., en adelante aseguradoras.

La nulidad de esta cláusula se plantea con los siguientes argumentos: a. Falta de voluntad clara e inequívoca de someter el asunto a arbitraje y de sustraerlo del conocimiento de la justicia.

b. La cláusula contempla un laudo arbitral que no produce el efecto de cosa juzgada.

c. La cláusula supone una renuncia genérica al Derecho Constitucional de acción.

d. Falta de determinación de la calidad de los árbitros.

e. La nulidad reclamada es parcial y no afecta al resto del contrato de seguro.

La parte demandada, a su vez, plantea una excepción dilatoria de incompetencia del tribunal $y$, en subsidio, la excepción de ineptitud del libelo por falta de algún requisito legal en el modo de proponer la demanda. Funda la excepción de incompetencia en los siguientes argumentos:

a. Que el tribunal carece de competencia para resolver esta materia, en tanto existe un contrato de seguro con inclusión de cláusula arbitral que obliga a las partes a so- 
meter las divergencias a un tribunal arbitral.

b. Que la cláusula es plenamente válida, en tanto no se ha declarado su nulidad.

c. Que la posible nulidad de la cláusula debe resolverse por el propio juez árbitro en virtud del principio Kompetenz Kompetenz.

\section{SOBRE EL PRINCIPIO \\ "COMPETENCIA - COMPETENCIA"}

\section{Bases y reconocimiento del principio.}

Este principio implica que debe ser el propio árbitro quien debe resolver los conflictos derivados del convenio 182 arbitral, incluida la posible alegación de nulidad del contrato del cual puede formar parte el pacto arbitral y aun de este último, lo que se resume en la idea de que el árbitro tiene competencia para revisar su propia competencia ${ }^{1}$. Esta potestad

${ }^{1}$ El principio Kompetenz-Kompetenz tuvo su origen en un fallo emitido por un Tribunal Superior en la República Federal de Alemania en el año 1955. En éste, se estableció que debía atribuírseles a los árbitros la facultad tanto de determinar el alcance del acuerdo arbitral como de su competencia y autoridad hacia el mismo. La CNUDMI (UNCITRAL, como comúnmente se conoce) adoptó oficialmente el principio Kompetenz-Kompetenz, estableciendo al respecto en el artículo 21, numeral 1 de su reglamento de arbitraje, lo siguiente: "El tribunal arbitral estará facultado para decidir acerca de las objeciones de que carece de competencia, incluso las objeciones respecto de la existencia o la validez de se entiende, desde una perspectiva positiva, como la manifestación o prolongación del convenio arbitral y sus efectos; y desde la óptica negativa, que los tribunales estatales quedan inhibidos de poder pronunciarse sobre esta materia por estar entregada a la justicia arbitral ${ }^{2}$. Su establecimiento y acogida se ha presentado en el marco de las legislaciones arbitrales comerciales internacionales más avanzadas, pero aún no se ha alcanzado la unicidad esperada, toda vez que las normas

la cláusula compromisoria o del acuerdo de arbitraje separado". Posteriormente, en 1985, estableció en el artículo 16, numeral primero: "Facultad del tribunal arbitral para decidir acerca de su competencia... El tribunal arbitral estará facultado para decidir acerca de su propia competencia, incluso sobre las excepciones relativas a la existencia o a la validez del acuerdo de arbitraje. A ese efecto, una cláusula compromisoria que forme parte de un contrato se considerará como un acuerdo independiente de las demás estipulaciones del contrato. La decisión del tribunal arbitral de que el contrato es nulo no entrañará ipso jure la nulidad de la cláusula compromisoria".

${ }^{2}$ Sobre las implicancias y connotaciones de este principio, véase entre otros, Miguel Gómez Jene, El arbitraje internacional en la Unión Europea: la eficacia del laudo arbitral, Madrid, Colex, 2000, p. 104; Juan CARDASO Palau, "Potestad de los árbitros para decidir sobre su propia competencia", en Julio González Soria (coord.) Comentarios a la nueva ley de arbitraje 60/2003, de 23 de diciembre, Navarra, Ed. Thomson-Aranzadi, 2004, pp. 255-267; Marta Gisbert Pomata, Comentarios a la ley de arbitraje. Ley 60/2003, de 23 de diciembre Madrid, coord. Rafael Hinojosa Segovia, $2^{\circ}$ Grupo de Difusión, 2008, pp. 135-139. 
no han logrado uniformar criterios sobre el particular ${ }^{3}$.

El principio en comento presenta una clara raigambre contractual en cuanto son las partes quienes le confieren una competencia total al árbitro para resolver un determinado asunto, de lo cual se deriva que éstos deben conocer incluso de su propia competencia para dar inicio al juicio arbitral y sólo si comprueba que éste es nulo o inválido, quedarán inhibidos de poder hacerlo. No se trata de una mera facultad del árbitro ni de una concesión de las partes a su competencia, se entiende que se trata de una obligación por parte del árbitro

\footnotetext{
${ }^{3}$ A modo de ejemplo, Francisco González de Cossío ha analizado el caso contrapuesto de dos sentencias, una mexicana y otra estadounidense, ambas pronunciadas por sus tribunales superiores de justicia, con un mes de diferencia durante el año 2006. La primera, llega a la conclusión que el acuerdo de arbitraje implica que un árbitro resolverá sobre la existencia y validez del contrato, pero dicha regla tiene una excepción, en el sentido de que cuando se demande nulidad del acuerdo arbitral mismo (no del contrato), será un tribunal estatal el que deberá pronunciarse sobre ello. La segunda, proclama que el acuerdo arbitral es autónomo del resto del contrato y la cuestión sobre la validez de este último debe ser considerada por el juez árbitro aun cuando se reclame la nulidad de todo el contrato (incluyendo, por tanto, la cláusula arbitral); por ende, la Corte sostuvo que el acuerdo arbitral es ejecutable al margen del resto del contrato y la reclamación debe ser considerada por el árbitro y no por la Corte. Francisco GonZÁlez de Cossío, "El principio competente-competence revisitado", en Revista de la Corte Española de Arbitraje, Madrid, 2007, pp. 63-91.
}

una vez que ha aceptado el cargo, aun a falta de mención expresa, pues tiene el deber de revisar los cimientos del juicio que va a conducir, de lo contrario, podrá constituirse en responsable ante las partes. Con todo, si bien el principio arranca de sede contractual, sus efectos se explican en verdad por medio de la ley, pues de lo contrario no sería factible que el árbitro pueda conocer del convenio que le sirve de antecedente a su competencia, si éste es nulo.

Este asunto engarza, además, con la autonomía del convenio arbitral al comprender que el acuerdo arbitral siempre debe entenderse separado del contrato del que pueda ser parte, de forma tal que la nulidad de éste último no pueda afectar la validez de la cláusula arbitral.

\section{Reconocimiento del principio en la legislación chilena}

En Derecho interno este principio no goza de consagración legal. Derivado de ello, la doctrina y jurisprudencia no han sido unívocas al determinar su aplicación, ya que, aun cuando resulta ser una consecuencia de un principio que si está reconocido, como es la autonomía del convenio, la recepción de aquél no ha logrado tener la misma acogida ${ }^{4}$. Así, normalmente se permite que el árbitro pueda pronunciarse sobre la existencia o

${ }^{4}$ Véase María Fernanda VÁsquez Palma, Arbitraje en Chile. Análisis crítico de su normativa y jurisprudencia, Santiago, Editorial Legal $\mathrm{Pu}-$ blishing, 2009, p. 350 y ss. 
nulidad del contrato en que se inserta materialmente el pacto arbitral, pero no cuando lo que se discute es la existencia o nulidad del acuerdo arbitral mismo, pues en tal caso se entiende que se estaría cuestionando la raíz de su competencia ${ }^{5}$.

Debido a lo anterior, se podría señalar que en el estadio arbitral doméstico se reconoce este principio a medias, es decir, el árbitro tiene competencia para conocer y pronunciarse sobre la validez del contrato del que forma parte la cláusula arbitral, mas no cuando lo afectado es el propio pacto que le confiere competencia, porque se estima que si se pone en tela de juicio aquélla, el árbitro podría resolver un asunto sin tenerla ${ }^{6}$, lo que equivale a asumir un

\section{círculo tautológico sin salida ${ }^{7}$.}

${ }^{5}$ En este sentido cabe citar, entre otros: fallo dictado por la CS, en Chilectra Metropolitana, con fecha 5 de abril de 1994; fallo dictado por la CA Santiago, en caso Carter Holt Harvey con Inversiones Socoroma, de 25 de julio de 1995; fallo de CS en Patricio Millas Ovalle con juez 25 Juzgado Civil”, de fecha 26 de marzo de 1996; fallo de CS en caso Sociedad Elizabeth Adauy y Cía. Ltda., de fecha 6 de octubre de 1993.

${ }^{6}$ Cfr. Osvaldo Contreras Strauch, Igor Kliwadenko Malic, Carolina LaRraín, Ricardo Peralta Larraín, Juan José Vives RoJAS, adhiriéndose a esta tendencia mayoritaria en la doctrina chilena, agregan como fundamento el carácter remunerado del árbitro y su posible parcialidad en resolver tal asunto, "Arbitraje y mediación en el seguro", VIII Congreso Ibero Latinoamericano de Seguros, celebrado en Rio de Janeiro, 2003, pp. 18-19.

${ }^{7}$ En esta línea, se encuentra la causa Aetna Chile Seguros Generales SA c. Leasing
En la LACI No 19.971 la situación es distinta, toda vez que -siguiendo la LMU- el principio presenta una clara consagración en su art. 16 que al efecto dispone:

"Facultad del tribunal arbitral para decidir acerca de su competencia.

1. El tribunal arbitral estará facultado para decidir acerca de su propia competencia, incluso sobre las excepciones relativas a la existencia o a la validez del acuerdo de arbitraje. A este efecto, una cláusula compromisoria que forme parte de un contrato se considerará como un acuerdo independiente de las demás estipulaciones del contrato. La decisión del tribunal arbitral de que el contrato es nulo no entrañará ipso iure la nulidad de la cláusula compromisoria".

\section{Correcta comprensión del principio}

Para la correcta comprensión de este principio, es preciso introducir algunos elementos que se adhieren a su diseño y, de la mano de ello, formular algunas matizaciones.

del Progreso S.A., en tanto la CS, señaló sobre la petición de nombramiento de un árbitro, que debía acogerse, en tanto le correspondía al árbitro pronunciarse sobre la controversia. En este juicio, no se reclamaba la nulidad de la cláusula arbitral, sino la falta de competencia del árbitro en relación con la materia (rationae materiae), de manera que la Excma. sigue el lineamiento antes esbozado. 
Tal como he señalado ${ }^{8}$, este principio implica que el árbitro no deberá interrumpir el procedimiento si se impugna su competencia en razón de inexistencia o nulidad $a b$ initio del contrato que contiene el convenio o si se impugna la validez de la cláusula que le otorga competencia. En ambos casos, quien debe resolver es él, dado que no hay lugar de sospecha a priori sobre el hecho de que los árbitros no estén al nivel o con la debida mesura para arribar por ellos mismos a una decisión a la vez equitativa y protectora de los intereses de las partes ${ }^{9}$. De esta forma, la competencia del árbitro se proyecta sobre un problema sustantivo, cual es, la validez o existencia del contrato que contiene el convenio arbitral y, por ello, ante la alegación de nulidad ab initio del contrato que contiene la cláusula, el árbitro se declarará competente para conocer y determinar su propia competencia y para ello examinará autónomamente el convenio arbitral que puede ser válido o $\mathrm{no}^{10}$. Derivado de ello, esta

\footnotetext{
${ }^{8}$ Véase Vásquez Palma (n. 4), pp. 212-213.

${ }^{9}$ Véase. José Carlos Fernández Rozas et al., Derecho de los negocios internacionales, Madrid, Iustel, 2007, p. 649.

${ }^{10}$ Como bien señala Elena Artuch Iriberri, la cuestión más controvertida de este principio se relaciona precisamente con la decisión del árbitro sobre la existencia y validez ab initio del contrato que contiene la cláusula, de forma que se otorga competencia al árbitro, sobre la base de una cláusula potencialmente inválida, para decidir sobre la causa de su competencia. Elena ARTUCH IRIBERRI, El convenio arbitral en el arbitraje comercial internacional, Madrid, Eurolex, 1997, p. 213.
}

regla y la de autonomía del convenio arbitral, se encuentran funcionalmente conectadas, ya que la finalidad de ambas es la de impedir la posibilidad de fuga a la jurisdicción del arbitraje pactado $^{11}$.

Como se puede apreciar, el fundamento que subyace a este planteamiento implica que el árbitro o tribunal arbitral debe estar conociendo del juicio arbitral o por comenzar a hacerlo, en tanto ya está constituido el tribunal. En tal sentido, el principio defiende la idea de que no se pueda arrebatar esta competencia al árbitro, pues es a él a quien le corresponde pronunciarse sobre dicha materia.

De este modo, no podemos pensar que este principio se aplique necesariamente cuando tal supuesto no se presente, esto es, el árbitro o el tribunal estatal aún no esté constituido. De hecho, podría ocurrir que las partes renuncien a dicha competencia si acuden conjuntamente al tribunal estatal o, bien, recurriendo una de ellas, la otra no se oponga y continúe litigando ante la justicia estatal.

Así, si una de las partes acude a la justicia ordinaria, esta última no puede dejar de conocer la alegación de nulidad del convenio arbitral presentada por aquélla, pues es su deber así hacerlo en tanto dicha materia también forma parte de sus atribuciones y competencia.

En nuestra opinión, el asunto debe resolverse sobre la base de una lógica común que se relaciona con la propia

${ }^{11}$ Siguiendo a GonZález y Cardaso PALAU (n. 2), p. 259. 
marcha del juicio arbitral. Así, si el tribunal arbitral está constituido, nada podría obstaculizar que sea él quien determine la validez del acuerdo arbitral si se plantea tal discusión en su sede, aun cuando luego tal resolución se revise por la justicia estatal en las oportunidades respectivas (revisión nulidad del laudo y ejecución del mismo), pero si dicho tribunal no está constituido, y es a la justicia estatalordinaria a la que se ha presentado la alegación de nulidad del acuerdo arbitral, ésta debe comprobar que dicho acuerdo es válido o eficaz, antes de derivar el asunto a la justicia arbitral. Con ello, no se deja de reconocer el principio "Competencia Competencia", sino que se le otorga un contexto viable y eficiente.

186
Ésta es la interpretación que debiera predominar, toda vez que es un hecho que el principio en comento ha evolucionado, y de concebirse que los árbitros eran los únicos que podían dirimir tal controversia ${ }^{12}$, hoy tal afirmación se ha moderado en el sentido de comprender que la justicia arbitral tiene una prioridad temporal respecto de la justicia estatal para pronunciarse sobre la validez y alcance del acuerdo arbitral, si este tribunal está constituido, de manera que no son los únicos facultados, sino, más bien, los primeros en pronunciarse sobre este asunto ${ }^{13}$, lo que busca garantizar, básicamente, que las partes

${ }^{12}$ De acuerdo con la Escuela Alemana.

${ }^{13}$ Más que un asunto de competencia, pasó a ser entendido como una materia de "temporalidad" de aquélla. no puedan paralizar o suspender fácilmente el procedimiento arbitral ${ }^{14}$ que ya se ha iniciado.

De acuerdo con lo ya señalado, no encontrándose constituido el tribunal arbitral, existiendo una alegación concreta de petición de nulidad del acuerdo arbitral en sede judicial, bajo argumentos que -como veremoscompartimos, procede que SS., conozca y resuelva la nulidad de la cláusula arbitral que aquí se propone.

A mayor abundamiento, debemos considerar que de acuerdo con lo estipulado en la cláusula arbitral respectiva, quienes pudieran ser nombrados como tal deben tener la profesión de ingenieros, que ninguna instrucción ni preparación tienen para conocer, ni resolver una materia de derecho estricto como es la nulidad de una cláusula arbitral.

\section{SobRE LA NULIDAD E INEFICACIA DE LA CLÁUSUla ARBITRAL}

\section{Aspectos generales a considerar}

Para que se comprenda y dimensione la importancia de este asunto, debe considerarse que el convenio arbitral no es un simple acto aislado, sino la piedra angular de la institución arbitral. Es causa de la competencia arbitral y correlativamente de la incompetencia de tribunales ordinarios

${ }^{14}$ Véase Eduardo Silva Romero, "Breves observaciones sobre el principio "KompetenzKompetenz", en El contrato de arbitraje, Bogotá, Editorial Legis, 2005, pp. 579-588. 
estatales, su validez impregna todo el instituto, incluida la sentencia ${ }^{15}$. De esta forma, si el convenio es nulo o ineficaz, y el procedimiento arbitral se sigue de todas formas, todo será nulo por la contaminación que necesariamente provocará el acuerdo arbitral en cuestión.

Pues bien, con carácter general, un convenio puede ser afectado, en cuanto a su eficacia, por tres tipos de causas: en razón de su invalidez por afectación de sus elementos esenciales; por inoperatividad y por error en el contenido del convenio. La validez del convenio arbitral se debe buscar en el principio rector de esta institución, esto es, "autonomía de la voluntad" de las partes que diseña los pilares básicos del arbitraje $\mathrm{e}^{16}$ y en la arbitrabilidad de la controversia que mira a la validez del convenio en cuanto a su objeto. El primero de los elementos es común a todos los contratos, de manera que en términos frecuentes se debe regir por las normas generales sobre el consentimiento, a menos que se dispongan normas adicionales; el segundo, en cambio, constituye un elemento particular de esta institución que busca determinar si la materia sometida a arbitraje (conflicto) es susceptible del mismo y como tal, habrá de buscarlo en los propios criterios diseñados por el ordenamiento en concreto.

${ }^{15}$ José María Chillón Medina y José Fernando Merino Merchán, Tratado de arbitraje privado interno e internacional, Madrid, Editorial Civitas, 1991, pp. 669-670.

${ }^{16}$ Véase Artuch Iriberri (n 10), pp. 176-177.
En el segundo elenco encontramos aquellas razones que hacen que el convenio resulte inoperante por haberse extinguido, es decir, habiendo sido válido y eficaz, ha devenido en inoperante como consecuencia, por ejemplo, de haberse dictado el laudo, por renuncia expresa o tácita de las partes, revocación, caducidad, incumplimiento del plazo para dictar sentencia, novación (siempre que la misma opere exclusivamente sobre el arbitraje pactado, lo que equivale a una renuncia del mismo), por transcurso del plazo señalado para el arbitraje, extinción tanto de la controversia como de la relación jurídica de la que éste deriva y, en suma, por todas las formas habituales de extinción de las obligaciones contractuales en la medida que éstas afecten y sean de aplicación al convenio arbitral ${ }^{17}$.

El tercero se relaciona con la insuficiencia o error en el contenido del convenio. En tal contexto, debemos distinguir al convenio patológico que es aquel que por defecto en la redacción, insuficiencia en el contenido, o errores en la determinación de sus elementos constitutivos resulta ineficaz para establecer el proceso y no puede cumplir las cuatro funciones que le son esenciales: producir efectos obligatorios entre las partes,

${ }^{17}$ Un análisis sobre la determinación de la inoperatividad del convenio arbitral, a propósito de dos sentencias australianas dictadas sobre esta materia en fecha reciente es efectuado por, Michael PrYLES, "Inoperative and operative arbitration agreements", in Journal of Internacional Arbitration, vol. 23, $\mathrm{N}^{\mathrm{O}}$ 3, The Hague, june 2006, pp. 228-238. 
apartar la intervención entre los tribunales estatales, conferir a los árbitros el poder para fallar la controversia y permitir la puesta en marcha del proceso arbitral; de aquél que, siendo defectuoso, puede prosperar luego de realizar una labor interpretativa, considerando para ello que no todos los errores cometidos en el convenio presentan idénticas consecuencias ${ }^{18}$.

Derivado de lo anterior, la sanción variará frente a la causal que aqueja al convenio arbitral. Si falta al convenio un elemento fundamental para su correcta configuración, el convenio será nulo; si, en cambio, opera la renuncia de las partes o la caducidad del mismo, el convenio no será nulo, pero si ineficaz de producir efectos; finalmente, si lo aqueja un error en su contenido, imprecisión o vaguedad, la sanción dependerá de la gravedad de aquéllas, si éstas no pueden salvarse, el convenio -siendo patológico- deberá entenderse igualmente como ineficaz.

\section{Convenio inválido}

El legislador no contempla un elenco detallado de las causales que pueden tornar ineficaz al convenio arbitral, razón por la cual ellas necesariamente deben estructurarse a partir de la lectura general de las normas que regulan los contratos, las particularidades del juicio arbitral y la aplicación

\footnotetext{
${ }^{18}$ Los errores más frecuentes son las cláusulas en blanco, designación de una institución inexistente o errónea, falta de forma de designación de un tercer árbitro, entre otras.
}

de la doctrina que se ha asentado en esta materia.

La nulidad del convenio arbitral se rige por las normas generales de los contratos ${ }^{19}$, de manera que si presenta un vicio aquél será anulable, a falta de regulación concreta sobre la materia, por diversas vías, incluida la acción de nulidad civil ${ }^{20}$. Como señalamos, por la propia naturaleza del pacto arbitral, una vez declarada, sus efectos alcanzan todo el proceso arbitral que se hubiere llevado a cabo a partir de este acuerdo, dado que se restituye a las partes al estado de derecho en que se hallaban antes del acto o contrato nulo (art. 1687 del Código Civil). La consecuencia no es menor, pues la acción civil de nulidad puede hacerse valer antes, durante y después de concluido el juicio arbitral, lo que provoca vulnerabilidad en las resoluciones pronunciadas en el juicio respectivo, incluida la sentencia arbitral pasada por autoridad de cosa juzgada que quedará desprovista de todo valor.

Para que el convenio arbitral se estime válido deberá cumplir con los requisitos generales establecidos para los contratos en el Código Civil.

${ }^{19}$ Así, por ejemplo, la CS ha fallado: "No es un acto procesal, sino un contrato de donde emana la jurisdicción del árbitro nombrado", puede hacerse aún después de ejecutoriada la sentencia arbitral, sin que sea necesario que se interponga en el juicio respectivo en forma y plazo señalados en la ley procesal, toda vez que se trata de infracciones de carácter sustantivo y no procesales". RDJ, tomo xxxviII, Santiago, 1941, sec. $1^{\circ}$, p. 396 .

${ }^{20}$ Véase art. 1681 y ss. del Código Civil. 
Sucintamente, el convenio debe contener una voluntad libre y exenta de vicios $^{21}$, un objeto y una causa lícita, y revestir las formalidades que se establecen para dichos efectos (art. 1445 y ss. del Código Civil). Además, las personas que convienen el pacto arbitral deberán tener la capacidad y legitimación requerida para cada uno de los casos. De la mano de lo anterior, el convenio arbitral puede ser nulo de nulidad absoluta y ello ocurrirá cuando adolezca de algún requisito esencial para su existencia, el consentimiento prestado esté viciado, no sea claro o esté incompleto, se ha suscrito por quien carece de legitimación o poder suficiente, se trata de un convenio prohibido, esto es, su objeto versa sobre materias inarbitrables, o es contrario a la ley o a las normas de arbitraje, tal nulidad no podrá sanearse por regla general ${ }^{22}$.

${ }^{21}$ Libertad que no sólo debe conjugarse desde el plano subjetivo sino, también, material, al tenor de lo dispuesto en el art. 228 del COT que prescribe: "Fuera de los casos expresados en el artículo precedente, nadie puede ser obligado a someter al juicio de árbitros una contienda judicial".

${ }^{22} \mathrm{Al}$ respecto, José María Chillón Medina y José Fernando Merino Merchán señalan que es preciso considerar que el carácter de insanabilidad de esta nulidad se ha puesto en tela de juicio, ya que se ha venido reconociendo por parte la doctrina y el derecho positivo la posibilidad de superponer a la nulidad de origen determinados remedios en los casos de compromiso incompleto, suscrito por quien carece de poder suficiente mediante la técnica de la ratificación o autorización posterior, y al compromiso carente de forma mediante la integración formal correspondiente. En

\section{Convenio ineficaz}

Que del convenio arbitral depende el resto del procedimiento arbitral y su existencia misma, no es una cuestión controvertida ni en la doctrina, ni en la práctica, en tal circunstancia el pacto arbitral deberá estar bien redactado porque el arbitraje es lo que es y no lo que las partes creen que $\mathrm{es}^{23}$. Es por ello que un completo estudio de una cláusula arbitral no termina en la valoración de su validez o invalidez, confrontada con las normas que sean aplicables, sino en un balance eminentemente práctico de su eficacia real, tanto positiva como negativa. En este sentido, podría ocurrir que un convenio siendo válido al inicio, se configure como imperfecto en la práctica, lo que lleva a separar lo "defectuoso de lo inválido" 24 .

Se trata de un conjunto de causales que la doctrina francesa, familiarizada con los problemas prácticos del arbitraje denominó "cláusulas arbitrales patológicas" por no involucrar las funciones esenciales que debe cumplir un acuerdo arbitral: producir consecuencias obligatorias, excluir la intervención de autoridades judiciales, dotar de facultades al tribunal arbitral para resolver la controversia y establecer un proce-

los demás supuestos se mantendría la regla general de la insanabilidad del compromiso nulo. Chillón Medina y Merino Merchán (n. 15), pp. 262-263.

${ }^{23}$ Cfr. María del Pilar Perales ViscasiLLAS, Arbitrabilidad y convenio arbitral, Navarra, Editorial Aranzadi, 2005, p. 97.

${ }^{24}$ Véase Artuch Iriberri (n. 10), p. 415. 
dimiento que bajo condiciones de eficacia y rapidez concluya en un laudo arbitral susceptible de ejecución $^{25}$. De esta forma, el convenio arbitral "patológico" no se extiende a aquellos supuestos en que éste es radicalmente inválido o nulo por una razón que afecte a su esencia misma, sino que es aquél que, siendo válido en lo medular, presenta imprecisiones cuya gravedad puede provocar la ineficacia del pacto ${ }^{26}$.

Ahora bien, siendo los pilares básicos de la validez del convenio $y$, por tanto, del arbitraje, la arbitrabilidad objetiva y la voluntariedad de las partes, se puede afirmar que los defectos más frecuentes se vinculan a éste último elemento, toda vez que la inarbitrabilidad en cuanto versa 190 sobre un problema íntimamente ligado al orden público, hace que su vulneración torne al convenio de arbitraje radicalmente nulo. Se trata, entonces, de vicios o ambigüedades de la voluntad de las partes que pueden tornar ineficaz el convenio ${ }^{27}$.

${ }^{25}$ Cfr. Fernández (n. 9), p. 648.

${ }^{26} \mathrm{El}$ origen de esta doctrina surge de lo dispuesto en el art. II del CNY, que establece tres tipos de causales de ineficacia del convenio, con carácter muy general. Se señala que los tribunales estatales respetarán el acuerdo por escrito entre las partes y enviarán a éstas al arbitraje, a menos que comprueben que dicho acuerdo es "nulo, ineficaz, o inaplicable". Sobre el particular, Véase Elena ARTuch IRIBERri, "La jurisdicción del CIADI de acuerdo con el art. 25 del Convenio de Washington", en RCEA, vol. xIv, Madrid, 1998, pp. 287-297; Fernández (n. 9), pp. 648-649.

${ }^{27}$ Elena Artuch Iriberri, señala que la práctica internacional es constante en afirmar

\section{Situación en la que se encuentra el acuerdo arbitral en referencia}

\section{A. Discusión jurídica}

La parte demandante, CMPC, solicita la nulidad absoluta de la cláusula arbitral suscrita con Chilena Consolidada Seguros Generales S.A. y Compañía de Seguros Cruz del Sur S.A., cuya continuadora legal hoy es RSA. Dicho acuerdo arbitral se insertó en forma de cláusula en la póliza de seguros denominada "Póliza de seguro todo riesgo construcción y montaje $N^{\circ} 1873002$ ". La redacción de la cláusula está efectuada en los siguientes términos:

"Todas las divergencias que surjan bajo esta Póliza, en relación con la indemnización a pagar, serán sometidas al dictamen de un árbitro a ser nombrado por escrito por cada una de las partes dentro de un mes calendario después de haber sido requerido por escrito para proceder así por cualquiera de las partes, o en caso de que los árbitros no estuvieren de acuerdo al dictamen de un dirimente nombrado por escrito por los árbitros antes de entrar a conocer el caso.

un principio general en estos supuestos que no es otro que la vinculación de los actos propios a quien los realizó. Se considera contravención de los actos propios el pacto de un convenio arbitral y posterior interposición de la excepción de incompetencia, cuando en el momento de la negociación del contrato en el inserto no fue discutido. ARTUCH IRIBERRI (n 10), p. 419. 
El dirimente actuará junto con los árbitros y presidirá sus reuniones. Los árbitros y el dirimente deberán ser ingenieros calificados. El laudo arbitral será condición precedente a cualquier derecho de acción contra la Compañía”.

B. Opinión legal sobre la nulidad de la cláusula arbitral en comento

De la sola lectura de esta cláusula emergen varias interrogantes que no plantean una fácil o única respuesta en relación con el consentimiento prestado por las partes. En efecto, de la redacción de esta cláusula se pueden formular diversas interpretaciones sobre algunos vocablos o frases que dejan evidencia su total falta de claridad. En especial, me referiré a las siguientes:

1. En la primera parte de la cláusula se señala que serán sometidas al dictamen de un árbitro

"todas las divergencias que surjan bajo esta póliza, en relación con la indemnización a pagar".

La redacción de esta parte del acuerdo es poco afortunada en tanto limita la labor del árbitro a una materia en concreto, como es el pago de la indemnización, sin quedar completamente claro si la causa basal de dicha obligación se comprende en dicho ámbito de actuación. En otras palabras, si el árbitro puede conocer de la declaración previa o de la causa que justifica la indemnización pactada, o ello debe hacerse por otro tribunal.

Para una correcta comprensión, la redacción de esta cláusula debiera haberse estipulado de la siguiente forma:

"Todas las divergencias que surjan bajo esta póliza, en especial, las que se susciten en relación a la indemnización de pagar, serán sometidas...”.

2. La palabra 'dictamen' también conlleva una dificultad de comprensión, toda vez que el árbitro, en derecho estricto, no emite dictámenes. En efecto, la palabra dictamen no es alusiva a la institución del arbitraje, sino a una similar que muchas veces tiene a confundirse con aquella, como es la figura del "perito dirimente" ${ }^{28}$. Los peritos dirimentes son personas que deciden o "dirimen" un determinado asunto, entregando un juicio de

${ }^{28}$ En este punto se debe considerar que los peritos pueden cumplir distintas actuaciones: 1. Puede intervenir emitiendo un dictamen que no vincula al tribunal, sino que constituirá un medio de prueba que se valorará por el juez (art. 425 del $C P C$ ); 2. Puede intervenir para resolver alguna desavenencia entre las partes (pericia dirimente); 3. Por otra parte, se encuentra aquella situación de valoración que realiza para completar un negocio jurídico, en este caso, no existirá conflicto entre las partes, sino un acuerdo en torno a que sea la voluntad de este tercero quien integre este negocio jurídico (arbitrio de un tercero); 4. Está, asimismo, su actividad, que no resulta vinculante para las partes al actuar como un perito mediador o conciliador. 
valor por medio del cual soluciona la cuestión planteada. Este imperio no les viene dado por su propia función, sino que procede de aquella atribución imperativa que ambas partes han concedido al perito cuando le eligen de común acuerdo. El objetivo de este peritaje ha de ser una cuestión pendiente entre los negociantes que dejan voluntariamente a la decisión de aquél o una cuestión surgida de un asunto previo que ellas someten a su juicio para esgrimirlas ${ }^{29}$.

Se aprecia, entonces, que el perito dirimente es aquella persona que por la voluntad contractual de las partes emite un juicio de valor (dictamen) vinculante para ellas, sobre una cuestión de hecho planteada por las mismas, que puede provenir de la aplica-

192 ción o interpretación de un contrato ya perfecto y que, por tanto, podría ser objeto de una mediación, de un arbitraje o de un litigio judicial ${ }^{30}$. Lo relevante de este asunto reside justamente en este punto, ya que la labor que realiza un perito, tal como hemos señalado, es distinta de la realizada por un tribunal arbitral. Así también, la fuerza que se concede a la decisión de un perito no es idéntica a la que

\footnotetext{
${ }^{29}$ Sobre el particular, véase VÁsQUEZ Palma (n. 4), pp. 26-30.

${ }^{30}$ Para Vidal Hernández López, no se trata de una pericia en el sentido ordinario, sino de la emisión decisoria de un juicio de valor o dictamen especial que por delegación o convención voluntaria de las partes las obliga a su aceptación y cumplimiento. Vidal HERnÁndEZ LÓPEZ, "Los peritajes dirimentes. Distinción con el arbitraje", en $A C, \mathrm{~N}^{\circ} 24$, tomo I, Madrid, 1988, p. 1.502.
}

emerge de un tribunal arbitral, pues ésta última es un equivalente jurisdiccional que puede exigirse por las vías contempladas a estos efectos, a diferencia de la anterior.

En tal contexto, podría ocurrir que las partes de esta causa no hubiesen tenido completamente claro a qué se estaban sometiendo al pactar esta cláusula, lo que implica aceptar un posible error en su consentimiento, máxime sin consideramos que la palabra dictamen se repite en dos ocasiones en la misma cláusula y ninguna referencia se hace en verdad, sobre la labor del árbitro, esto es: que conozca y resuelva la controversia en cuestión con efecto de cosa juzgada.

3. Otro aspecto nebuloso que plantea la redacción del acuerdo arbitral se encuentra al finalizar la primera parte, que señala:
“o en caso de que los árbitros no estuvieren de acuerdo, al dictamen de un dirimente nombrado por escrito por los árbitros antes de entrar a co- nocer el caso".

Lo que no logra explicar esta redacción es en qué no habrían de estar de acuerdo los árbitros. Lo lógico es que tal desacuerdo se relaciona con el laudo o sentencia a que finalmente arriben, entonces, ¿ cómo podría explicarse que los árbitros deban nombrar a un dirimente "antes" de "entrar a conocer el caso"? Claramente se trata de una redacción confusa que 
no tiene una fácil interpretación.

Por otra parte, ¿qué se entiende por dirimente? Si bien debiera pensarse en la figura del un "tercer árbitro" que formará parte del tribunal, de la última parte de la cláusula no queda perfectamente especificado, toda vez que allí se realiza una clara distinción entre la persona de los árbitros y la del dirimente haciendo pensar que se trata de dos figuras completamente diferentes ("los árbitros y el dirimente deberán ser ingenieros calificados").

4. Por su parte, la cláusula dispone:

"El laudo arbitral será condición precedente a cualquier derecho de acción contra la Compañía".

¿Qué implica la redacción de esta cláusula? Ciertamente podríamos considerar que no se trata de un arbitraje, sino de un peritaje dirimente que no es vinculante para las partes, toda vez que se deja entrever que la decisión ejercida por los "árbitros" por medio del laudo, será una condición precedente a cualquier derecho de acción contra la compañía, de manera tal que sólo una vez que exista tal pronunciamiento las partes podrán acudir a los tribunales estatales con el objetivo de ejercer una acción contra la misma, lo que se da justamente en el dictamen de un peritaje que no tienen el mismo valor que un laudo arbitral.

Asimismo, debiéramos pensar que este "dictamen" sólo sería obligatorio para la compañía aseguradora, lo que fuerza la extrañeza del asunto, toda vez que a ésta no se le faculta para acudir al tribunal ordinario en contra de la asegurada, sino sólo a ésta última o, bien, podría estar considerándose como un hecho que el dictamen sólo podrá ser perjudicial para la asegurada, y nunca para la aseguradora, lo que podría explicar también la curiosa redacción del acuerdo en comento.

De cualquier forma, el asunto es que si el laudo será condición precedente a cualquier derecho de acción, ello implica asumir que la decisión de los árbitros no tendrá la fuerza de resolver el asunto de una manera definitiva, lo que por cierto vulnera la naturaleza de la institución arbitral que se concibe justamente para tal efecto de manera alternativa a la justicia estatal.

Por el contrario, y de estimar que en este acuerdo sólo se dice algo evidente en tanto se estipula que el laudo del tribunal arbitral será recurrible ante otro tribunal, lo cierto es que nuevamente nos encontramos con un dilema, toda vez que si el tribunal debe ser conformado por "ingenieros" éste debiera resolver en "equidad", de manera tal que la sentencia que se dicte a estos efectos sólo podría ser recurrible ante un tribunal de igual naturaleza, y no ante tribunales ordinarios, cuestión que claramente no podrá realizarse, pues el acuerdo no nombra un tribunal arbitral de equidad de segunda instancia. De cualquier forma, estimamos -según veremos a continuación-que este tribunal arbitral tampoco podría 
ser considerado de equidad, pues nada se señala sobre el particular y, de acuerdo con nuestro Derecho, para que así pueda estimarse se requiere mención expresa.

5. En el evento que se estime que se trata de un acuerdo arbitral, es preciso considerar que la cláusula nada señala sobre la calidad de los árbitros ni del arbitraje, de manera tal que debiera entenderse que se ha pactado un arbitraje de derecho de acuerdo al artículo 235 del $C O T^{31}$, sin embargo, en la citada cláusula se señala: "los árbitros y el dirimente deberán ser ingenieros calificados", lo que contraviene el Derecho chileno, toda vez que de acuerdo con el art. 225 del COT, el árbitro de

194 Derecho sólo puede tener la calidad de abogado ${ }^{32}$. Así, este arbitraje no podrá nunca prosperar por cuanto los árbitros que se nombren a estos efectos no podrán ejercer un arbitraje de Derecho, pues no serán abogados, pero tampoco podrá ser considerado de equidad, pues no se previó de dicha forma.

A este respecto, conviene recordar que el art. 223 del COT, prescribe:

"Los árbitros de derecho se someterán, tanto en la tramitación como en el pronunciamiento

${ }^{31}$ Que dispone: "Si las partes no expresaren con qué calidad es nombrado el árbitro, se entiende que lo es con la calidad de derecho".

${ }^{32}$ Así lo han fallado también los tribunales de justicia. Véase Vásouez Palma (n. 4), pp. 80-81. de la sentencia definitiva, a las reglas que la ley establece para los jueces ordinarios, según la naturaleza de la acción deducida...”.

Lo anterior equivale, en líneas generales, a que en un procedimiento seguido ante uno de estos árbitros se aplicarán las normas comunes a todo procedimiento y las normas legales establecidas para cada tipo específico, lo que no obsta a la facultad de las partes para acordar la supresión de ciertos trámites, la agregación de otros y cualesquiera otras modificaciones en el procedimiento legal, toda vez que constituye un principio general que las partes pueden renunciar a sus derechos conferidos por las leyes con tal que miren en su sólo interés individual y no esté prohibida su renuncia ${ }^{33}$.

En resumen, conforme con lo revisado precedentemente, el acuerdo arbitral adolece de graves vicios que provocan su nulidad o, a lo menos, su ineficacia e inoperatividad, lo que se resume en la idea de que no existe una clara manifestación de las partes en cuanto a someterse a la justicia arbitral, además de la existencia de una

${ }^{33}$ Esto resulta de la aplicación del principio de renunciabilidad consagrado en el art. 12 del Código Civil. Asimismo, en los procedimientos seguidos ante jueces ordinarios las partes también pueden efectuar renuncias de sus derechos cuando miran en su propio beneficio (ejemplo, arts. 7, 125, 155 del $C P C$ ), razón por la que nada impide que las partes realicen lo mismo ante un árbitro de Derecho. 
redacción que lo hace ininteligible, lo que fuerza indefectiblemente su pérdida de eficacia.

Tal falta de claridad puede ser justificada a priori por el tipo de contrato que han suscrito las partes. Se trata de un contrato estándar, redactado por el asegurador probablemente en otro idioma -desde donde ha sido traducido al castellano- lo que dificulta a la parte asegurada tener un completo control sobre la comprensión y redacción de la misma. La naturaleza de este contrato ha generado diversos debates sobre si puede considerarse que se presta un verdadero consentimiento ${ }^{34}$. Sobre la base de ello, normalmente la justicia estatal chilena se ha involucrado en la revisión de dichas cláusulas ${ }^{35}$.

Los vicios relatados son del todo manifiestos, de manera que de acuerdo con lo preceptuado en el art. 1683 del Código Civil, tal declaración podría efectuarse, incluso, de oficio por SS.

En atención a los hechos expuestos, normativa y principios legales precedentemente citados, procede que se declare la nulidad, ineficacia o ambas de la cláusula arbitral en referencia. De no llegar a tal resultado,

${ }^{34}$ Aludiendo básicamente al carácter abusivo que pueden tener muchas de estas cláusulas. Sobre la materia, véase A. Antonio Aljure Salame, "El arbitraje y el contrato de seguros en el derecho nacional e internacional", en El contrato de arbitraje, Bogotá, Editorial Legis, 2005, pp. 361-376.

${ }^{35}$ Sobre la concreta materia de los contratos de seguros, Véase Vásouez Palma (n. 4), pp. 527-536. podrá acontecer que se siga un juicio arbitral y, luego, una vez que la sentencia arbitral se dicte, todo se torne inválido a partir de los vicios que aquí se han vislumbrado, que tal como señalamos, son variados y graves.

Es todo cuanto puedo informar.

\section{BibLIOGRAFÍA}

Aljure Salame, Antonio, "El arbitraje y el contrato de seguros en el derecho nacional e internacional", El contrato de arbitraje, Bogotá, Editorial Legis, 2005.

Artuch IrIberri, Elena, El convenio arbitral en el arbitraje comercial internacional, Madrid, Eurolex, 1997.

Artuch IrIBERri, Elena, "La jurisdicción del CIADI de acuerdo con el art. 25 del Convenio de Washington", en RCEA, vol XIV, Madrid, 1998.

GonzÁlez de Cossío, Francisco, "El principio competente-competence revisitado", en Revista de la Corte Española de Arbitraje, Madrid, 2007.

Cardaso Palau, Juan, "Potestad de los árbitros para decidir sobre su propia competencia”, en Julio GonzÁlez SORIA (coord.) Comentarios a la nueva ley de arbitraje 60/2003, de 23 de diciembre, Navarra, Ed. ThomsonAranzadi, 2004.

Contreras Strauch, Osvaldo, Igor Kuiwadenko Malic, Carolina LaRraín, Ricardo Peralta Larraín, Juan José Vives Rojas, "Arbitraje y mediación en el seguro", en VIII Congreso Ibero Latinoamericano de Seguros, Rio de Janeiro, 2003.

Chillón Medina José María y José Fernando Merino Merchán, Tratado de 
arbitraje privado interno e internacional, Madrid, Editorial Civitas, 1991.

Fernández Rozas, Juan Carlos et al., Derecho de los negocios internacionales, Madrid, Iustel, 2007.

Gisbert Pomata, Marta, Comentarios a la ley de arbitraje. Ley 60/2003, de 23 de diciembre Madrid, coord. Rafael Hinojosa Segovia, $2^{\circ}$ Grupo de Difusión, 2008.

Gómez Jene, Miguel, El arbitraje internacional en la Unión Europea: la eficacia del laudo arbitral, Madrid, Editorial Colex,, 2000.

GonzÁlez Soria, Julio (coord.) Comentarios a la nueva ley de arbitraje 60/2003, de 23 de diciembre, Navarra, Ed. Thomson-Aranzadi, 2004.

GonzÁlez de Cossío, Francisco, "El principio competente-competence revisi- de Arbitraje, Madrid, 2007

Hernández López, Vidal, "Los peritajes dirimentes. Distinción con el arbitraje", en $A C, \mathrm{~N}^{\circ} 24$, tomo I, Madrid, 1988.

Perales Viscasillas, María del Pilar, Arbitrabilidad y convenio arbitral, $\mathrm{Na}$ varra, Editorial Aranzadi, 2005.

Pryles, Michael, "Inoperative and operative arbitration agreements", in $\mathrm{Jo}^{-}$ urnal of Internacional Arbitration, vol. 23, No 3, The Hague, june 2006.

Silva Romero, Eduardo, "Breves observaciones sobre el principio "Kompetenz-Kompetenz", en El contrato de arbitraje, Bogotá, Editorial Legis, 2005.

Vásquez Palma, María Fernanda, $A r$ bitraje en Chile. Análisis crítico de su normativa y jurisprudencia, Santiago, Editorial Legal Publishing, 2009. 